\title{
Correction to: Consequences of Labour Migration on Wages and Employment: Evidence from India
}

\author{
Mohd Imran Khan ${ }^{1}$
}

Published online: 6 March 2021

(C) Indian Society of Labour Economics 2021

\section{Correction to: The Indian Journal of Labour Economics https://doi.org/10.1007/s41027-020-00294-7}

There were some errors identified in the article after publication. The corrected text is given below.

Last line in the third paragraph under Section 3 was incorrect and it should read as follows:

Scheduled Caste, Scheduled Tribes, Other Backward Caste, Muslims, and Others. (For descriptive statistics table, see Appendix Table 3.)

First line in the second paragraph under Section 4 was incorrect and it should read as follows:

As reported in appendix Table 3, migrants earn a higher daily wage than nonmigrant workers in the labour market and have higher workforce participation rates and lower unemployment rates than non-migrants.

The citation of Table 1 was incorrect; it should be placed in Sect. 5.1. The complete Sect. 5.1 should read as follows:

\subsection{Overall Impact of Migration on Wages and Employment}

The following section presents the estimated results of both IV and non-IV estimates. In Table 1, the OLS estimates show that the impact of migrants on the wage earnings of non-migrant workers is positive and significant (column 1). A $1 \%$ point increase in migration in a region increases the daily wage earnings of non-migrant workers by less than half a per cent. The OLS estimates may be biased because migrants choose destination labour markets that offer higher wages. After controlling for the endogeneity of migration, the coefficients are still

The original article can be found online at https://doi.org/10.1007/s41027-020-00294-7.

Mohd Imran Khan

mohdimran.khan@nmims.edu

1 Sarla Anil Modi School of Economics, NMIMS, Mumbai, Maharashtra, India 
Table 1 Impact of migration on wage and employment

(1)

OLS

IV

(A) Impact of migration on wages

\begin{tabular}{lll} 
Share of migrants in a district & $0.004 * * *$ & $0.028^{* * *}$ \\
Constant & $(0.001)$ & $(0.006)$ \\
& $1.505^{* * *}$ & $4.239^{* * *}$ \\
Observations & $(0.291)$ & $(0.806)$ \\
$R$-squared & 17,973 & 17,973 \\
$F$-statistic & 0.542 & 0.473 \\
Kleibergen-Paap rk LM statistic & & 198.5 \\
Kleibergen-Paap rk Wald F-statistic & & 98.87 \\
Hansen $J$ statistic & & 77.92 \\
\hline & & 0 \\
\hline B) Impact of migration on employment & Probit & IV-Probit \\
Share of migrants in a district & & 0.002 \\
& & $(0.003)$ \\
Constant & 0.000 & $-0.984 * *$ \\
Observations & $(0.000)$ & $(0.291)$ \\
First stage $F$-statistic & $-1.146^{* * *}$ & 109,968 \\
Wald statistic & $(0.157)$ & 1042.34 \\
Wald test of exogeneity & 109,968 & 22,828 \\
\hline
\end{tabular}

Robust standard errors in parentheses. ${ }^{* * *} p<0.01,{ }^{*} * p<0.05, * p<0.1$. Dependent variables: logarithm of daily wages and worker participation as a binary variable. All the regression equations use controls such as education, socio-religious groups, married, age and its square, 14 broad industries, district unemployment rate, share of population with secondary education and above, per capita district domestic product, and state dummies. The regressions with other controls are provided in supplementary file Table S1 and Table S2. The district sample size is 443. Instrument variable: the migration rate in a district in 2007-2008 is instrumented with the rate of migration in 1991

positive as shown by the IV estimates in column 2 of Table 1 . The estimates show that migration increases the wage earnings of non-migrant workers by $2.8 \%$ and that the coefficients are statistically significant. We also looked at the impact of migration on the employment of non-migrant workers, which is shown in Table 1 Panel B. The estimated results show that the employment participation of nonmigrants is not affected by the inflow of migration as both IV and non-IV estimates are statistically insignificant in column 3 and column 4 of Table 1, Panel B, respectively.

The estimated results are contradictory to the textbook labour market model which predicts a negative effect on wages. Empirical studies conducted in developed countries find a small but negative effect of immigration on native wages (Peri 2014). Our estimates are consistent with the studies (Friedberg 2001; Kugler 
and Yuksel 2008) which found that migrants and non-migrants are not close substitutes and suggest a complementary relationship between them.

Publisher's Note Springer Nature remains neutral with regard to jurisdictional claims in published maps and institutional affiliations. 